SUS-RURI: Proceedings of a Workshop on Developing a Convergence Sustainable Urban Systems Agenda for Redesigning the Urban-Rural Interface along the Mississippi River Watershed held in Ames, lowa, August 12-13, 2019

\title{
Dubuque, lowa: Building a Sustainable Community on the Mississippi River
}

\section{Gina Bell ${ }^{1}$}

${ }^{1}$ City of Dubuque

Published on: Jan 14, 2020

DOI: 10.31274/3d9ea6a4.0ba37c81

License: Creative Commons Attribution 4.0 International License (CC-BY 4.0). 
The facilitator introduced the Lunch Keynote speaker, Gina Bell. Originally from the Dubuque area, she went to college and then joined the Peace Corps and worked in Paraguay. After returning to the States, she took positions mostly on the West Coast. Currently, works as the Sustainable Communities coordinator in the city of Dubuque.

\section{Gina Bell}

I am really excited to be here. For those of you who are not from Iowa or around here, Dubuque is located where Iowa, Illinois, and Wisconsin come together. It is the cultural commercial, and educational center for the area.

It is also a part of the Driftless area, which is the part of North America that escaped all three phases of the Wisconsin glaciation. Most people think of Iowa as flat, but that is not what Dubuque is. We are right in the middle of the Mississippi watershed, and we recognize that our actions impact those downstream. In turn, we are also impacted by other Mississippi River cities and towns. Dubuque has many limestone bluffs, and we recognize ourselves as a river town. It is a part of our identity and our culture is very much linked to it. I will share a little bit of Dubuque's history, how we have worked to grow our community in a more sustainable way, and looking forward, how we are going to continue to address the impacts of climate change.

Early on in Dubuque, it started with boat building, brewing, and the railroad industry. Dubuque was chartered in 1833. It is Iowa's oldest city, and it was mostly covered with limestone bluffs and savannah oaks, which were promptly chopped down and used in lots of different industries, which changed a lot of the water runoff. The curve runoff water pre-settlement number was 45 , and post-urbanization, it is up to 76.7. The curve runoff number is the standard calculation used to determine storm sewer system sizing in detention basin design, and we are now dealing with some of those impacts.

Dubuque fell on hard times: In the early 60s and 70s, it was doing really well, with a low unemployment rate. Then the farm crisis and economic crisis in the 80 s hit hard. Our major manufacturing employers laid off many people. We had the highest unemployment rate in the nation in 1982, at $23 \%$, creating a lot of brownfields during this time. The motto at the time was, "Will the last one out of Dubuque please turn off the lights?"

In the 90s, Dubuque reinvented itself instead of closing up shop. We got a new motto: "Will the last one out of the room please turn off the lights?" We were some of the early 
adopters of the EPA Brownfield grants and started redeveloping our river, in fact, reconnecting ourselves to our river. We focused on sustainability, job creation, tourism and recreation, as well as technology. In 2005, our mayor, who is still our mayor today, was elected on his platform of sustainability.

It was not called sustainability at the time, but he talked about the economy. He talked about our neighbors and equity, about the environment and how it is important, and how our connection to the river is really important. This also coincided with him having his first grandchild, so he started thinking about legacy. He has been a very proactive mayor and pushed hard to have my position created and to put Dubuque at the forefront of some sustainability initiatives. In 2013, we adopted a $50 \%$ by 2030 plan in 2013 to reduce our greenhouse gas emissions.

We continue to work on this goal and came up with this great vision statement: Dubuque is a sustainable and resilient city in an inclusive, equitable community; we have preserved our masterpiece on the Mississippi; we have a strong, diverse economy, and expanding connectivity; and our residents experience healthy living and active lifestyles, have choices of quality, livable neighborhoods, an abundance of fun things to do, and are engaged in community. 


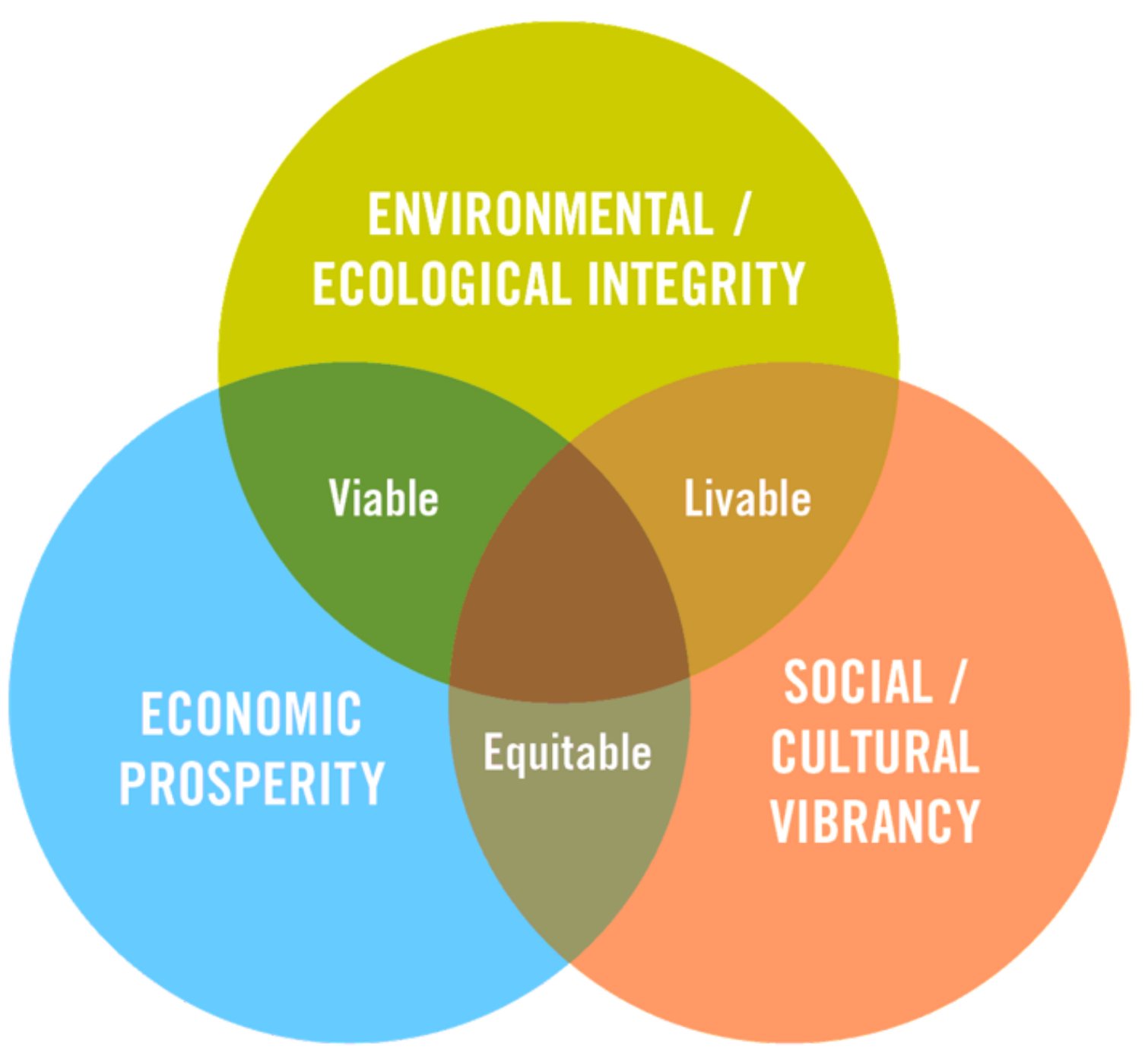

The premise of all of my work is based on this diagram behind us. We see sustainability as the ability to meet the needs of the present without compromising the ability of future generations to meet their own needs. Sustainable Dubuque is a holistic approach to how we do everything within our city and what we are controlling, as well as what our community does and how we can encourage the larger community to do this as well.

Sustainable Dubuque has 12 principles-each falls within one of three buckets:

1. Environmental ecological integrity-healthy air, clean water, native plants and animals. 
2. Reasonable mobility in terms of economic prosperity: we look at our regional economies, smart energy use, how we manage our resources, and community design.

3. Social and cultural vibrancy: we look at green buildings, access to healthy local foods, our community knowledge, and our community health and safety.

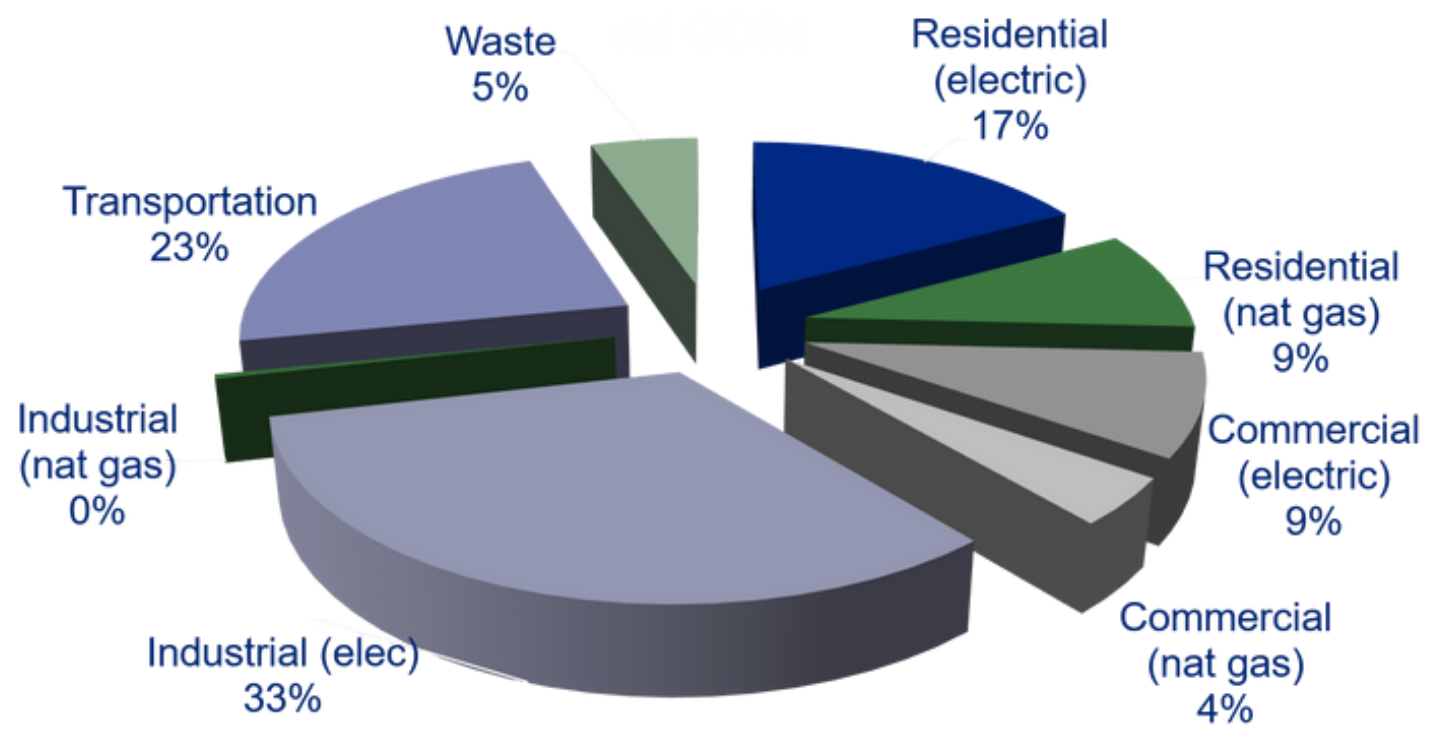

This was our baseline greenhouse gas inventory in 2003, which we're working toward. The $50 \%$ by 2030 is a non-binding, voluntary effort to identify opportunities to reduce our greenhouse gas emissions. We look at it as a way to strengthen our economy and overall quality of life in the community, as well as do our part to address climate change. We use it to inform our local officials to make better choices, and we are in the process of updating our climate action and adaptation plan. We work with individual city departments to start budgeting for the impacts of climate change. We use it to inform businesses and individuals in the community about potential emissions and cost savings opportunities. It helps us showcase success stories and provide the template for emerging reduction opportunities that can be added at later dates. And of course, we use it as an educational piece as well.

The $50 \%$ by 2030 was introduced as a way of looking at potential reductions and, as of 2018 , we are at a $27 \%$ reduction - so we are over halfway there. In our update of our future climate action and adaptation plan, we will be setting future goals. While I 
would like to get up and say in front of crowds that the world is ending in 2030, I also have children and have to think beyond that. So, we will be setting future goals for Dubuque.

We talk a lot about resiliency and climate adaptation in Dubuque. There is strategic planning, land use planning and code development, infrastructure investments, emergency preparedness, and recovery and community engagement. All those things fall within the city, but also rely on the residents. One of our challenges is that while we feel we are doing a lot, regionally, we want to do more. Our geographic location makes us feel very much connected to Illinois and Wisconsin, but regionally, we are often lumped in with the rest of Iowa. Because we feel this disconnect, we are looking for ways to also work with not only Wisconsin and Illinois, but the rest of Iowa as well.

We have seen a lot and talked a lot about flooding as our city developed - people built houses that were prone to floods because they were in the floodplain of the changing Mississippi. In 1965, we had a major flood, and the city decided to take action and build a flood wall. So thankfully, in 1970, we had this beautiful flood wall and levee system, which continues to provide the city with protection. But it took us 50 years to do anything beyond that, which you will learn about in our Bee Branch watershed project I'll speak to later on.

Looking at our floodwall and our levee, we see that there are still many weaknesses. We know that there are other cities and towns along the Mississippi that do not have this protection, and the effort needs to be focused on them, but we are still trying to figure out how to fund the continued maintenance on what we already have so that we are being proactive rather than reactive.

There is more precipitation predicted for Iowa-we are expecting about a $23 \%$ increase, and a lot of this will happen in the spring and summer, which is prime flooding season. We keep looking at what is happening and what we are experiencing, but we also know that Iowa, over the last 122 years, has had about a 15\% increase in annual rainfall already. While we do not know what lies ahead exactly, we have many models, yet things seem to be happening at a really rapid rate.

We look at flood hazard overlay districts which are updated by FEMA. Often, we use these to assess where to offer building permits and to determine what can be developed in the flood plain and what should not be developed in the floodplain. Insurance companies use this data as well. We want to make sure that folks who are 
taking some of these risks have flood insurance. We also use them to promote public health and safety and general welfare for our residents.

In Dubuque, already we have seen many impacts of climate change, even though we have our great levee and floodwall. We have seen more frequent and extreme rain events as well as heat events-earlier this summer we saw concrete buckling throughout the city. Droughts, tornadoes, and very high asthma rates. Then there is loss of property value, loss of income on our investments, infrastructures lacking or in need of maintenance/repair.

In addition, there are social impacts. We know and have heard earlier today that our most vulnerable populations will be the ones that are impacted the most. We are working to address what resiliency looks like at a neighborhood scale, and it can sometimes be as simple as making sure that people know their neighbors and that their neighbors are checking in on them. It is only one step to doing this, but it is really time-intensive work. I am a department of one, but what I do is what I feel passionate about, and I recognize that the people with the least are going to be hit hardest.

We are also looking at potential population influx and what that means for Dubuque. We did lose about $10 \%$ of our population in the early and mid-80s, but as people moved in from the coasts, or are looking for a place that is a little bit more climate resilient, that may have an impact on Dubuque's population.

This spring flood of 2019 was record-breaking. From March 20th to June $13^{\text {th }}$, we recorded 86 continuous days when the river stage was at flooding levels - our longest stretch of flooding ever. The previous record was 37 days in 2001. Our flood control operations for the city lasted 108 days and the river crested above 20 feet three times during that period. Our operations budget for flood control was 92\% over budget.

Many things contributed to this "the perfect storm," but I think will see more perfect storms as the climate continues to change. We had above normal precipitation in the fall which kept river stages pretty consistent throughout the winter when we had saturated and frozen soils. There was high runoff, an extreme amount of snow, and then higher than normal spring rains. All of which played a role in the historic spring floods. But what we are expecting to see these scenarios to become the new normal.

An additional challenge we faced in Dubuque was that when we went to the close our flood gates in anticipation of flooding, there were 36 inches of ice that we had to melt 
first in order to close our flood gates. This was the first time that our public works department had to deal with this condition and that we now have to budget for.

In terms of sustainability, Dubuque has put in a lot of effort. We have solar power on our fire stations and on our public works building. This not only helps with our greenhouse gases emissions, but it also helps making buildings more resilient. We are also working on our intermodal transit center and our operations center, which consists two separate buildings. We will hopefully be adding more solar on those as well.

We had a great partnership with Alliant Energy to build two solar fields. One is right in downtown Dubuque, built on a brownfield right near the river and also serving as an educational piece. West of Dubuque is the largest solar bright field in Iowa.

We also took on a huge capital improvement project to update our wastewater treatment facility. It was reconstructed in 2013, a \$70 million project-the largest undertaking that Dubuque had done at the time. It went from being our biggest energy user to saving the city about $\$ 600,000$ a year in energy costs. It not only treats the wastewater from the city, but also takes in industries' high strength waste and then uses that to create methane, which powers the plant and potentially will power vehicles in the future.

In addition, we have the Bee Branch Creek Watershed project, which is a flood mitigation project that directly addresses the changes in climate in the city of Dubuque. The project is focused on managing the increasing, intense rainstorms, the resulting flash flooding, and the damages that it causes to homes and businesses in the floodplain in the area. Floods are caused by too much water arriving at the same place, and all of the water wants to go into the river at once. As I was showing in an earlier photo, Dubuque has this low-lying area along the river with big limestone bluffs. The Bee Branch Creek was buried, originally, into a storm sewer over 100 years ago. We have since day-lighted it and created not only an area for this water to go, but also a linear park. We have an orchard, which has become a community gem. This is the artist's rendition of what was called then the Curler Valley, which is now the Bee Branch. You can see that the bluffs, which once were covered in oak, have no trees left on them. But there are several homes and businesses that located in this area. 


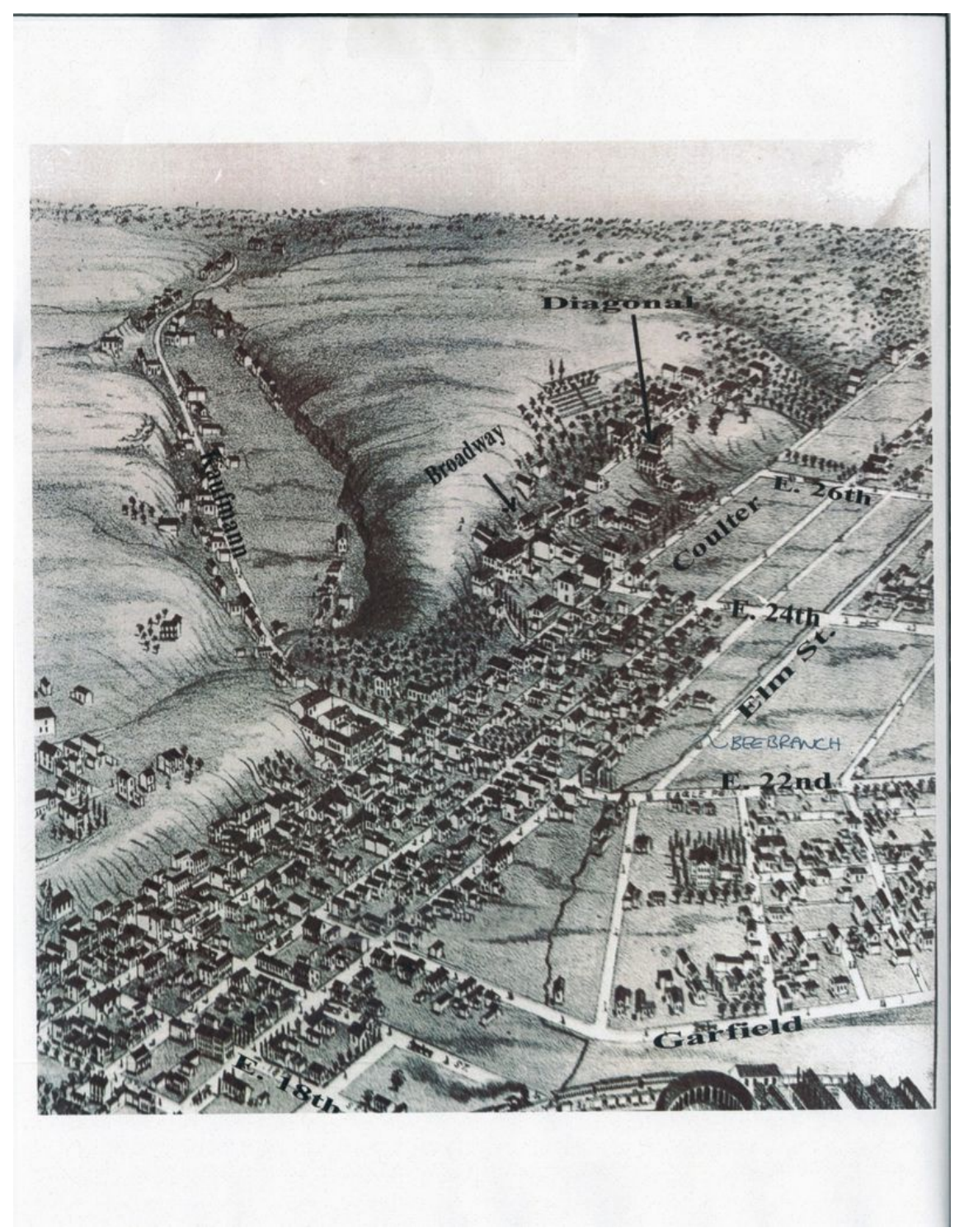

As we saw more increased rain events, we identified issues with limestone foundations. Even if the storm sewer was not flooding into the streets, it was seeping into people's basements. People that lived in this area for a while knew that when it rained, there was water in their basement. 


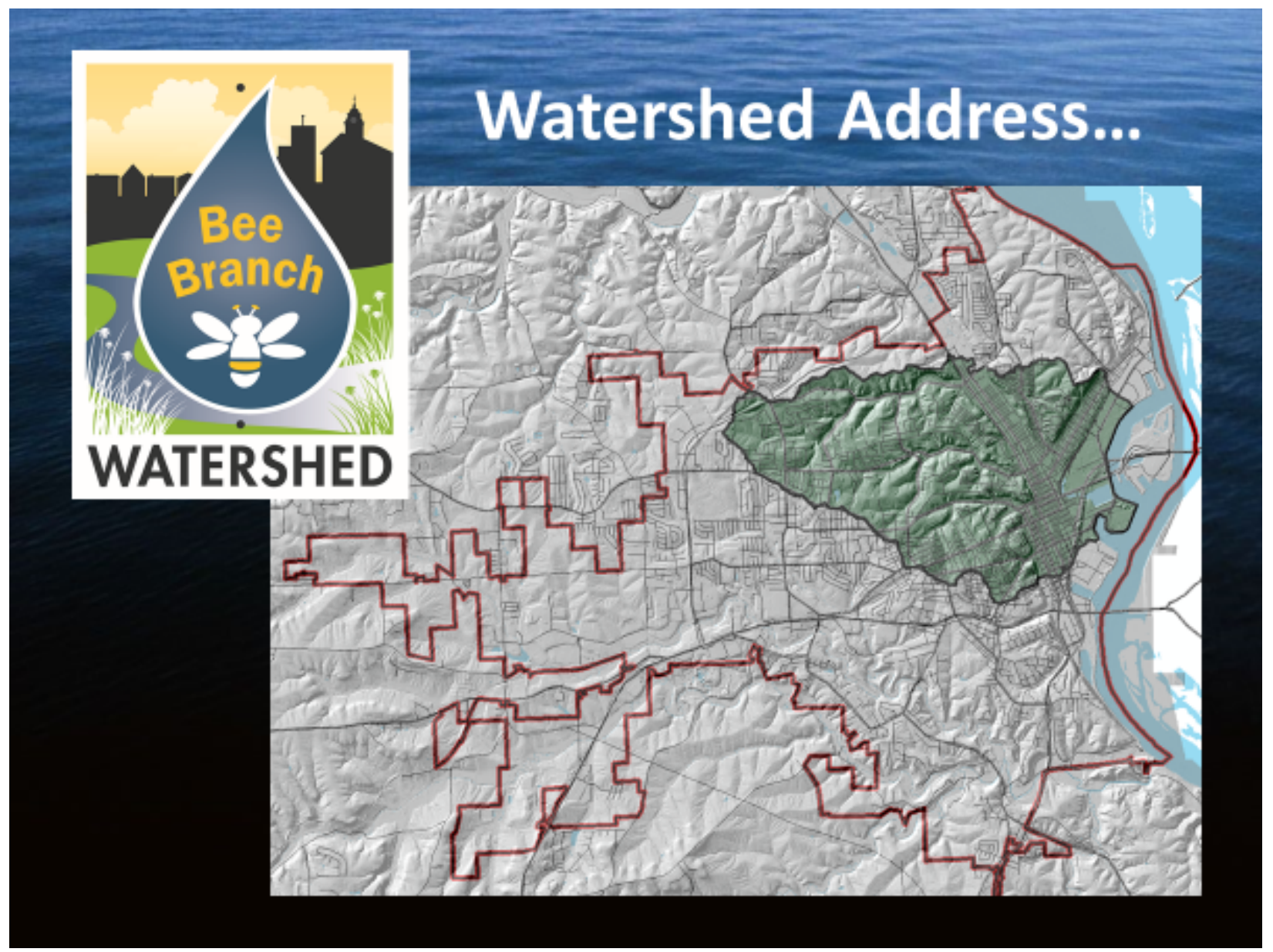

Here is the watershed address, specifically of the Bee Branch watershed, resulting not only increased precipitation, but also caused by increased development on the West End. Up the bluff, we started paving farmlands, which only increased the amount of water that was coming down. With more precipitation and more sealed surface lots, more water is pushed down the bluffs. 


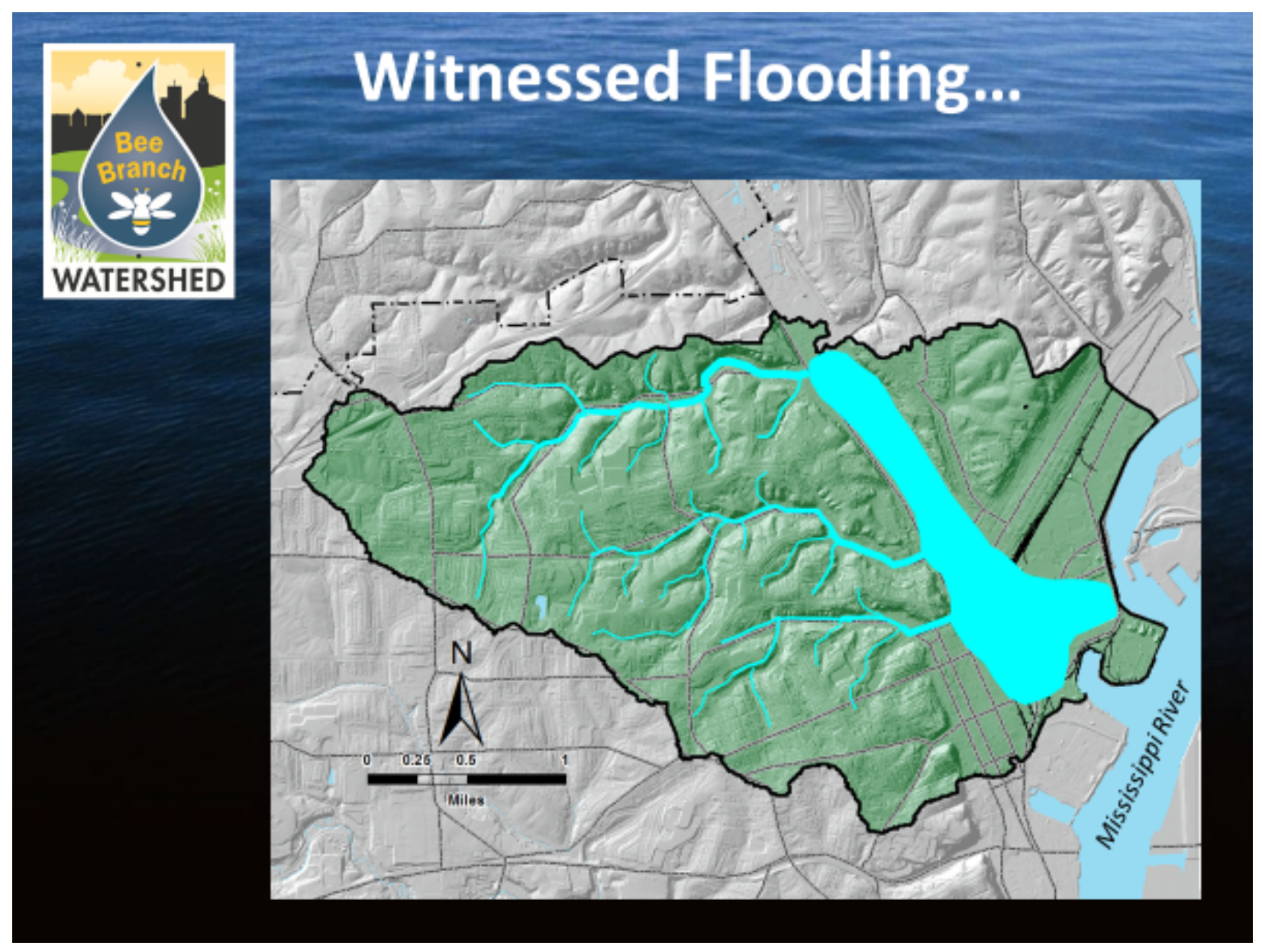




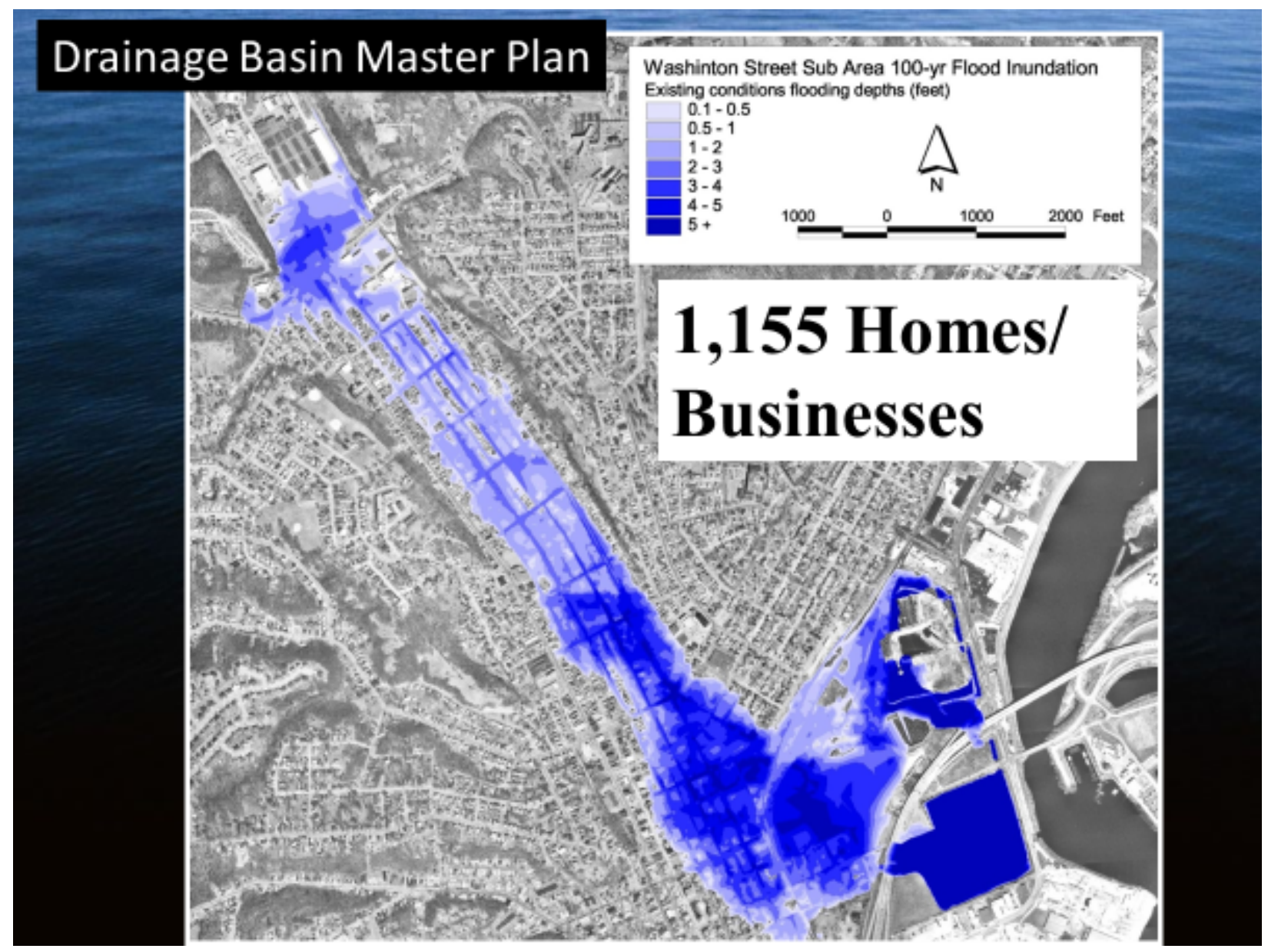

The storm water flows really quickly to the same place, with no safe place to go. This is another look at the 100-year flood inundation existing. We worked with engineering consultants and there were about a little over a thousand homes and businesses that risked flooding every time that it rained in Dubuque. Those are shown in blue.

Then, between 1999 and 2011, heavy rains produced flash flooding in the Bee Branch watershed six times. Resulting damage prompted presidential disaster declarations. Homeowners were forced to repair or replace damaged property, and the city felt the urge to act.

We now know that 100-year storms are now considered 50-year storms. After each rain event, the city would take calls, and the fire department would go out and pump people's basements out; however, this service is a huge resource burden. Since the work on the Bee Branch watershed was completed, there were no more calls for - they dropped from over 200 to zero. 
In those six declared disasters, there was about $\$ 70$ million in damages, and the relief for the families that were living with the continued flooding is immeasurable. The mitigation project will reduce the volume of stormwater, slow the rate and timing, and increase safe stormwater conveyance throughout the flood-prone area. We implemented a green alleyway program, which is pervious pavement that will reduce the volume of the water reaching the system. We have converted several streets with permeable pavers, and several more are on the list pending funding.

The Department of Transportation has been a partner in this as well as the EPA. We also created some upstream detention basins, which also slow the flood waters. These were completed back in 2014, in collaboration with the Army Corps. The two detention basins that collect water create a beautiful wildlife refuge as you drive down different streets in the city.

The completion of a holding pond removed a lot of asphalt from the area, and now it serves as an actual pond. We still have one step to go - building culverts under a railroad. It has taken us 17 years to get permission from the railroads, so we just broke ground on last week. Once this is finished, it will eliminate the last stop to getting the water to the Mississippi River.

In addition to the resiliency aspect of it, we also have this great "healthy homes project". We went into the homes that consistently had mold and water damage issues as well as suffered from high asthma rates. We replaced hot water heater, furnaces, and washing machines and put in permeable pavers to address some of the other issues that are associated with rain events in these homes in order to make these this area more vibrant and more resilient. We also connected people to other services that address related social issues.

From a practitioner's point of view, it is really important to be able to translate the work that being done and the data being collecting into what is real. How can we impact people's lives and what does the data mean in real life? For Dubuque, we looked at what data around precipitation and flash flooding meant, and created this huge, really expensive project. However, the value of the results is much greater than any amount of money that we spent.

Another challenging issue is related to nitrogen and phosphorus, because it is part of the whole watershed area. We shouldn't be concerned just about what we are doing in Iowa and Illinois, we also have to think about down river. 
Then there is the Growing Sustainable Communities conference. It is in its 12th year, held at the Grand River Center, which is part of the Brownfield Redevelopment. It offers two and a half days of programming, and Katharine Hayhoe will be there. More information is available at gscdubuque.com.

\section{The facilitator encouraged questions from the audience:}

\section{Mary Dilate}

I am the executive director of the Great River Passage Conservancy, here together with my colleague Angie. We are located in St. Paul focus on the 17 miles the strategic development of the Mississippi River. What you were talking about was very interesting. One of the things that we worry about in St. Paul-because a good portion of our river is actually a working river-is the impact of flooding on business. You referenced the fact that 80 some odd days, the river was at peak flood stage. Similarly, in St. Paul, we had that problem, which meant businesses were shut down because barges were not able to move. I'm wondering if you are addressing any of that, or if you're sort of consulting with people about the future of business along the river.

\section{Gina Bell}

That is a great question. I don't have any concrete answer for you, but we are certainly talking about this issue and trying to engage businesses in these conversations.

\section{Josh Sperling}

I represent the National Renewable Energy Lab. I was surprised when you said you were saving $\$ 600,000$ per year on the new wastewater treatment plant. I am curious to learn more. On a whole different scale, or order of magnitude, with $\$ 70$ million in damages from one flooding event, how do you address investment strategies? One of the questions we are exploring is, "How do we value resilience?" and how are you approaching quantifying that or communicating it to the public?

\section{Gina Bell}

Thank you. This is one of the things that I think can be really impactful: looking at what is the cost of doing something preventively vs. reactionary. In our updated climate action plan, that is one of the things that we have asked our consulting firm to look at specifically. 
I do think that this is the story we have to tell, because so much is based on economics. How much will it cost, and what are the benefits to me? Even with the Bee Branch, you talk to the homeowners and they say, "This changed my life. For 60 years I dealt with water in the basement. I wish my wife could have lived here you know to see this happen," and then I talked to a friend of mine, who says, "Well I think it was a waste of taxpayer dollars." Because it doesn't impact him; he lives up the bluff.

This event is supported by the National Science Foundation, Award \#1929601. Any opinions, findings, and conclusions or recommendations expressed in this material are those of the author(s) and do not necessarily reflect the views of the National Science Foundation. 